\title{
The burden of gynecological cancer management in Northern Nigeria
}

\author{
Adekunle O. Oguntayo ${ }^{1 *}$, Marliya Zayyan ${ }^{1}$, Mattew Akpar ${ }^{1}$, Abimbola O. D. Kolawole ${ }^{1}$, \\ Sunday A. Adewuyi ${ }^{2}$ \\ ${ }^{1}$ Department of Obstetrics \& Gynaecology, Ahmadu Bello University, Teaching Hospital, Zaria, Nigeria \\ ${ }^{2}$ Radiation Oncology, Ahmadu Bello University, Teaching Hospital, Zaria, Nigeria \\ Email: "fayokunmi@yahoo.co.uk
}

Received 19 September 2013; revised 16 October 2013; accepted 23 October 2013

Copyright @ 2013 Adekunle O. Oguntayo et al. This is an open access article distributed under the Creative Commons Attribution License, which permits unrestricted use, distribution, and reproduction in any medium, provided the original work is properly cited.

\section{ABSTRACT}

Background: Carcinoma of the Cervix is one of the gynecologic cancers. Gynecological cancer is a scourge in the developing nations because of the burden of cervical cancer. Carcinoma of the cervix is the leading cause of cancer death in women. The costs of treatment of cancers generally are very high and this has made care very difficult in the developing nations. The question therefore is who bears the cost and whose responsibilities? Aims and Objective: To study the economic burden of cancers on the patient, and how they source for these funds. To determine how the lack of funds or otherwise has affected their care. To assess their perception of who should bear the cost of this care. Methodology: It is a prospective study of all consecutive patients that attended the Gynecologic clinic of our unit between $2^{\text {nd }}$ January 2010 and $30^{\text {th }}$ June 2010. Data were analyzed using Excel statistical package. Result: A total of 93 patients were interviewed. A majority of $70(76 \%)$ of the patients had Carcinoma of the cervix. The mean age of there husbands was 58 years. Most of them were either farmers $(21 \%)$ or retired civil/public servants $(15 \%)$ and earn between 700 - 1700 dollars per year. A large group of the patients were full time House wives (48\%), while Petty trading and farming account for $13.3 \%$ each. The women earn less than 500 dollars per year. Only $\mathbf{5 0 \%}$ received assistance, from family members $(35.8 \%)$ or relatives $(29.6 \%)$. More than $50 \%$ of them have spent between 1000 - 3000 dollars for their health bills. It was sad to note that $40 \%$ of them have no hope of help/assistance from anywhere. A majority of $83.3 \%$ believe that the government should come to their aids. Conclusion: In the developing nations, poverty still remains major problem,

\footnotetext{
${ }^{*}$ Corresponding author.
}

where people still earn less than a dollar per day. In essence prevention is paramount; otherwise most of our women who escaped maternal mortality may end up being a victim of cancer death.

Keywords: Burden; Cancers Gynecological; Northern; Nigeria

\section{INTRODUCTION}

Gynaecological cancers in developing countries remain a big challenge to the gynaecological Oncologist. Knowing fully well that it is the disease of the low socio-economic group [1], as such the economic burden on the patients and their relations are usually overwhelming. The American Cancer Society estimates that about 570,000 cancer deaths occur each year in the United States. Cancer is the second leading cause of deaths after heart disease in America. In Africa Cancer is an emerging public health problem [2]. According to the International Agency for Research on Cancer (IARC), about 715,000 new cancer cases and 542,000 cancer deaths occurred in 2008 in Africa [2]. These numbers are projected to nearly double (1.28 million new cancer cases and 970,000 cancer deaths) by 2030 simply due to the aging and growth of the population [2].

It is estimated that one out of every two men and one of every three women will have cancer in their lifetimes. About one in four persons will die of cancer [3]. It is a major burden or scourge in Northern Nigeria [4]. The most common gynaecological cancer is carcinoma of the cervix which is the most common cancer in women in Northern Nigeria and the leading cause of cancer death in women in developing nations [2,4]. High incidence of Carcinoma of the Cervix is a major contributing factor to the epidemiology of gynecologic cancers in the develop- 
ing nations. Carcinoma of the Cervix accounts for $74.8 \%$ of all Gynecologic cancers in Nigeria [5]. Other gynecological cancers include ovarian, endometrial, vagina, vulva and chorio-carcinomas.

The World Bank income categories classifies Nigeria as a low income earners group [6,7]. An average Nigerian earns less than a dollar per day. Facts and figures show more than $70 \%$ of the Nigerian Population live below the poverty line i.e. proportion receiving less than $\$ 1$ per day in income (purchasing power parity) [6,7]. Nigeria also accounts for $8 \%$ of the world's total poor who live in each nation. ("Poor" here is defined as living below the global poverty line of US\$1 per day) [6-10]. Such individual will not be able to cope up with his or her bills.

The cost of treatment of cancers generally is very high and this has made care very difficult in the developing nations. The average cost of Care for Cancer of the cervix in Zaria, Northern Nigeria is estimated at $\$ 1500$. In view of the economic facts and figures with respect to our economic status and health, it is almost impossible for an average person to offset his/her health bill in respect of cancer. Another important factor that needs to be considered is the fact that most of these women are the bread winner of the family and as such we can not isolate them from the care of the other family members. The Labor force; female (\% of total labor force) in Nigeria was last reported at 42.84 percent in 2010, according to a World Bank report published in 2012. Female labor forces as a percentage of the total show the extent to which women are active in the labor force. Labor force comprises people ages 15 and older who meet the International Labour Organization's definition of the economically active population [11].

Medical cost-effectiveness analyses traditionally treat patients as isolated individuals and neglect the effects of improvement in patients' health on the welfare of their family members [12]. The cost of oncology drugs is not the only elephant in the room when addressing the costs of cancer care, Dr. Eagle appropriately points out that "provision of more aggressive care by physicians, the prolongation of the period of treatment and patient survival, and changes in the site of care," all in an aging population, are important drivers of the rising costs [13]. Within this context, understanding two intertwined aspects of oncology care becomes mandatory: the costvalue dissociation of interventions in oncology; and the misalignment of incentives among payers, providers, patients, and industry $[12,13]$. In the United States, oncologic drugs led all classes in drug spending in 2011, and the increasing cost of the drugs further worsens the problem [12]. The magnitude of the problem is all encompassing because other components such as imaging, radiotherapy, surgical procedures are equally beyond the reach of an average Nigerian.

The burden of cancer care in Nigeria will definitely increase with improvement in care, as the number of cancer survivor's increases. Also improvement in life expectancy will increase the number of aged population which will increase the cancer rate [14].

In Nigeria we have health insurance policy but it does not cover cancer care compared to the developed countries $[15,16]$.

Studies done at the centre for disease control and prevention in America revealed that the cost of cancer care has almost double, between 1987 and the 2001-2005 period, the total medical cost of cancer increasing to $\$ 48.1$ billion from $\$ 24.7$ billion because more people are getting cancer and living longer [17].

We want to study the economic burden of gynecologic cancers on our patients, and how they source for funds.

Secondly to evaluate how the lack of funds or other-wise affects their care and finally to assess these women's perception of who should bear the cost of these care.

\section{METHODOLOGY}

It is a prospective study of all consecutive patients that attended the Gynecologic and Radio-oncology clinic of the Ahmadu Bello University Teaching Hospital, Zaria, Kaduna State, Nigeria between $2^{\text {nd }}$ of January 2010 and $30^{\text {th }}$ of June 2010, who consents to the study. A structured self administered questionnaire was utilized. The questionnaire was pretested to ensure that it suit the objectives of the study. Consent to participate in the study was obtain by verbal means.

The patients recruited for the study where those who have been diagnosed histologically or biochemically and have commenced treatment.

Data generated were analyzed using Excel statistical package 2007. The component of the analysis was on descriptive analysis, using mean, median, mode, percentages, ratio, and standard deviation. We also apply demographic representations where necessary.

\section{RESULT}

A total of 93 patients were interviewed during the study period. Majority 70 (76\%) of the patients had Carcinoma of the cervix. The mean age of their husbands was 58 years. More than half (42) of the husbands were either dead, farmers or retired from active service, see Figure 1. While a large groups (43\%) of the patients were full time House wives; others are into farming, trading, civil service or retired. See Figure 2. Forty three and forty percent of the patients suggested that the government and their relatives respectively should bear the cost of the treatment, while others suggested religious group, community leaders, friends and etc. See Table 1. About 71 

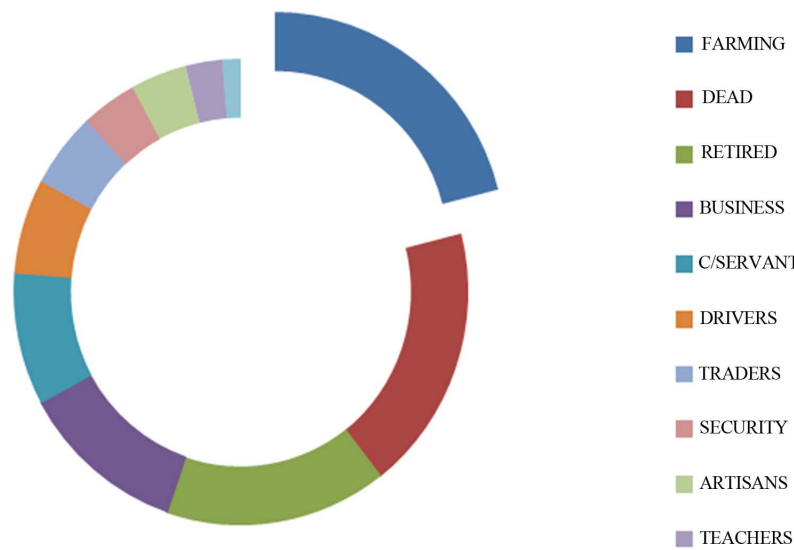

Figure 1. Husbands occupation.

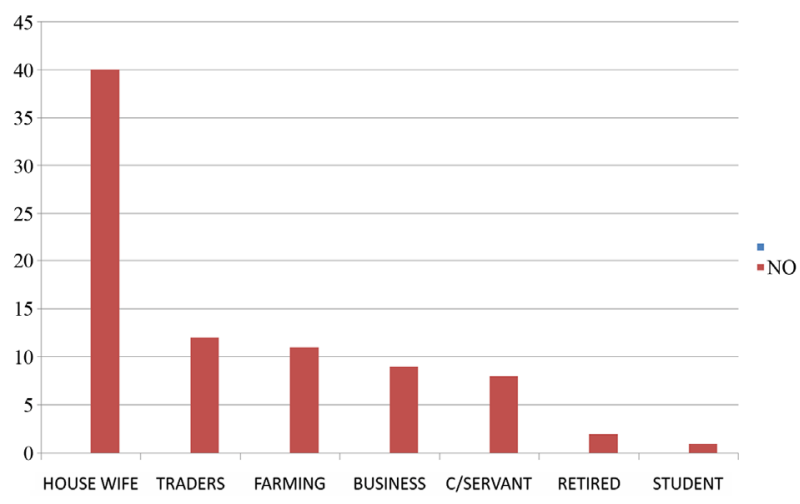

Figure 2. Wifes occupation.

Table 1. Suggested/source of assistance for the Gyne-oncology patients.

\begin{tabular}{ccc}
\hline & Source & Suggested Source \\
\hline Source & No & No \\
Family & 19 & 3 \\
Relatives & 16 & 24 \\
God & 3 & 0 \\
Friends & 3 & 3 \\
L/Government & 3 & 26 \\
Good Samaritan & 2 & 0 \\
Hospital & 2 & 2 \\
Community Head & 1 & 0 \\
Religious Gp & 0 & 2 \\
Total & 49 & 60 \\
\hline
\end{tabular}

percent of them were assisted by their family or relatives. See Table 1.

Majority of the women who were working or employed forty one (55\%) earn "between” \$700 - \$1700 per annum. while (40\% of the women) earn "between” $\$ 10$ $\$ 10,000$ per annum. Fifty one (68\%) of them have spent between $\$ 700$ - $\$ 2050$ towards achieving treatment, with a ratio value of 0.84 See Figure 3 .

The illness has affected them in various aspects, ranging from work to social life and emotion. More than fifty percent of them admit one form of effect or the other on their work and social life. Surprisingly the disease complex has not significantly affected there emotions. See Table 2.

\section{DISCUSSION}

Poverty still remains a major problem of the developing Nations. An average Nigerian earns less than a dollar per day [6,7]. Considering the mean age of the husbands in this study as 58 years makes majority them to be at the point of retirement or are retired. See Figure 1.

Majority of the husbands who were working were farmers. The women were mainly House wife's earning in the range of $\$ 10$ - $\$ 10,000$ per year. The main support of these patients has been from their relatives, which was actually in the spirit of communal assistance notable for Africans. The mind set of the people is that of seeking help or begging to survive or relying on government support. These patients should not be blamed for looking up to the government, because health care delivery in the past used to be free and lately cancer care was free by the government in Nigeria.

In view of the poor earnings, the cost of treatment, the

Table 2. The effect of cancer on patients work, social activity \& emotion.

\begin{tabular}{cccccc}
\hline & $\begin{array}{c}\text { No } \\
\text { effect }\end{array}$ & $\begin{array}{c}\text { Little } \\
\text { effect }\end{array}$ & Quit a bit & Very much & $\begin{array}{c}\text { No } \\
\text { response }\end{array}$ \\
\hline Work & 42 & 14 & 13 & 18 & 6 \\
Social activity & 41 & 24 & 10 & 18 & 0 \\
Emotion & 54 & 9 & 19 & 5 & 6 \\
Total & 137 & 47 & 42 & 41 & 12 \\
\hline
\end{tabular}

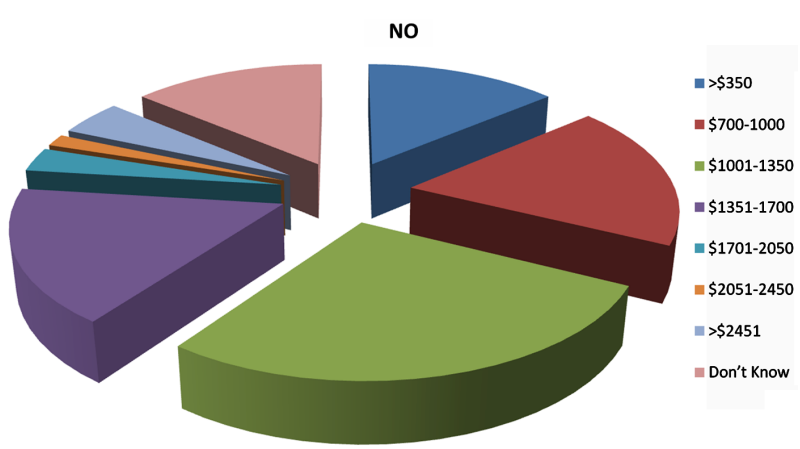

Figure 3. Amount in $\$$ spent as at the time of the study by the individual patients. 
amount majorities have spent and what they will need to spend, our patients should not be blamed for the following inadequacy in there management or care.

Under utilization of the screening methods especially for cancers that has meet the entire requirement for screening. Cancer of the cervix is one cancer that has been relegated to a point where it is no longer a public health problem. In our own environment it is the leading cause of cancer death in women and second to carcinoma of the breast as the commonest cancer in women $[2,4]$. The aforementioned is also glaring in this study as the commonest gynecologic cancer.

At the moment vaccination against human papilloma virus, so as to protect the girl child against carcinoma of the cervix in the future is only utilized by a few elite who can afford it. No wonder most gynecological cancers remain the disease of the low socioeconomic class.

Late presentation to the hospital is a common finding. Most (70\% - 75\%) of our patients present late to the hospital and as such they could only benefit from palliative care, with very poor prognosis and high mortality [5].

Incomplete treatment is the order of the day amongst our patients, mostly because they lack funds to complete the treatment, poor compliance because of side effect, as majority of the patients presents late and combination therapy are usually instituted [5].

At other times the equipment may brake down not fully functional because of unstable, poor power supply.

Default of Treatment is another limiting factor to successful care for cancer patients essentially because of lack of funds. Andrew advice in his own study that the physician and patient should determine the appropriate course of treatment with a patient's choice of therapy subject to his or her health status and financial ability [13]

Some Absconds from hospital beds or sign against medical advice, others suffer on the hospital bed until they submit to nature and some others just accept it as the "Act of God" when they ran out of funds.

\section{CONCLUSIONS}

Oncologists and their patients face difficulties in making a choice as to appropriate investigation and course of treatment of a particular cancer, in view of the cost implication affordability, availability of equipment and manpower.

The issue of care and cost is ongoing in cancer management, as treatment options often require a long term commitment in a rapidly changing technologies which are expensive to develop and maintain.

We need to redirect our focus which set our priorities right as a Nation, Region and Continent towards reducing or eradicating this scourge of our time (cancers in women); otherwise most of our women who escaped maternal mortality may end up being a victim of cancer death.

The government should consider the free treatment that was applied in the past for all our cancer patients, especially among women who are not economically empowered, and whose decision are tied to that of their own husbands and at risk of complex variety of cancers compared to their male counterparts.

The National Health Insurance Scheme needs to include cancer screening and treatment in the scope of care for the scheme or else many of our patients will continue to die unassisted.

\section{REFERENCES}

[1] Merletti, F., Galassi, C. and Spadea, T. (2011) The socioeconomic determinants of cancer. Environmental Health 2011, 10, S7.

http://www.ehjournal.net/content/10/S1/S7 http://dx.doi.org/10.1186/1476-069X-10-S1-S7

[2] Ferlay, J., Shin, H.R., Bray, F., Forman, D., Mathers, C.D. and Parkin, D. (2008) GLOBO-CAN 2008, cancer incidence and mortality worldwide: IARC cancer-base No.10. International Agency for Research on Cancer, Lyon. http://globocan.iarc.fr

[3] Quinn, P., (2011) Cancer and your environment in cancer in illinois.

http://www.idph.state.il.us/cancer/factsheets/cancer.htm

[4] Mohammed, A., Ahmed, S.A., Oluwole, O.P. and Avidime, S. (2006) Malignant tumours of the female genital tract in Zaria, Nigeria: Analysis of 513 cases. Annals of African Medicine, 5, 93-96.

[5] Oguntayo1, O.A., Zayyan1, M., Kolawole, A.O.D., Adewuyi1, S.A., Ismail1, H. and Koledade1, K. (2011) Cancer of the cervix in Zaria Northern Nigeria. Ecancermedicalscience, 5, 219.

[6] Organization for Economic Co-operation and Development, Development Assistance Committee (DAC). (2002) Online database and data on GDP from World Bank, Paris.

[7] Human Development Report 2006, United Nations Development Programme; World Bank, 2002. World Development Indicators 2002. CD-ROM. Washington, DC.

[8] Adebola, S.A. (2008) An overview of developments in Health Care Administration in Nigeria (1960-2005). In: Saliu, H.A., et al., Eds., Perspective on nation-building and development in Nigeria, Concept Publications Limited, Lagos.

[9] Ugbolue, H. and Olabi, O. (1997) Begging for a living. The News Magazine, 9.

[10] World Health Organization (WHO). (2001) Correspondence on access to essential drugs. Department of Essential Drugs and Medecines Policy. Geneva.

[11] Labor force; female (\% of total Labor force) in Nigeria in trading economic of the World Bank data compiled 2010 and published 2012.

[12] Jonas, A. and de Souza, M.D. (2012) The cost of cancer 
care: There is more than one elephant in the room. Oncology, 26, 926-928.

[13] Rettenmaier, A.J. (2012) Healthcare financing and the cost of cancer care. Oncology, 26, 924; 926.

[14] Cancer trends progress report 2011/2012 update. (2012) National Cancer Institute, U.S National Institute of Health. www.cancer.gov

[15] Metiboba, S. (2011) Nigeria's national health insurance scheme: The need for beneficiary participation. Research
Journal of International Studies, 22, 51-56.

http://www.eurojournals.com/international studies.htm

[16] Chemo, F.X. (2009) A product of precision therapeutics. Precision Therapeutics Inc., Pittsburgh.

[17] Tangka, F.K., Trogdon, J.G., Richardson, L.C., Howard, D., Sabatino, S.A. and Finkelstein, E.A. (2010) Cancer treatment cost in the United States: Has the burden shifted over time? Cancer, 116, 3577-3484. 